\title{
Chapter 3 \\ The Prevention of Chronic Diseases Through eHealth: A Practical Overview
}

\author{
Dario Monzani and Silvia Francesca Maria Pizzoli
}

\section{Introduction}

The implementation of effective prevention programs delivered through eHealth technologies is a promising approach to prevent the onset and progression of chronic conditions as P5 underlines. Specifically, eHealth prevention interventions combine the effectiveness of the traditional preventive programs with substantial advantages and functionalities of the new technologies.

Indeed, eHealth prevention interventions allow to target larger segments of population, by giving each individual tailored and real-time feedback (cfr. Chap. 4) about personal risk and behaviors (Baker 2001; Evers 2005; Fotheringham et al. 2000).

Nowadays, chronic diseases are the leading cause of disability and mortality all over the world (World Health Organization 2009, 2017). According to the World Health Organization, chronic diseases are illnesses with a slow progression and prolonged duration; they generally do not resolve spontaneously and could be treated but rarely cured completely (World Health Organization 2017). They could be defined as health conditions lasting 3 months or more that could not be prevented by vaccines or cured by medications (MedicineNet 2016). Time duration and the fact that symptom control is the primary scope of the cure render chronic conditions a relevant issue for patients and for the healthcare system.

All chronic conditions are characterized by four main common qualities (Australian Institute of Health and Welfare 2016). First, they are typified by complex and multiple causalities because their onset and progression are influenced by

D. Monzani $(\bowtie) \cdot$ S. F. M. Pizzoli

Department of Oncology and Hemato-Oncology, University of Milan, Milan, Italy

Applied Research Division for Cognitive and Psychological Science,

European Institute of Oncology (IEO) IRCCS, Milan, Italy

e-mail: dario.monzani@ieo.it; silviafrancescamaria.pizzoli@ieo.it 
several interacting factors, such as genetic, environmental, and behavioral factors. Second, chronic conditions generally start with early developmental phases that are often asymptomatic and then develop slowly. Third, they display a prolonged course of illness that generally flows into other related health complications. Finally, chronic diseases lead to several and serious impairment or disability. Heart disease, cancer, type 2 diabetes, arthritis, Alzheimer' disease, depression, HIV, hypertension, chronic respiratory diseases, and asthma are among the most prototypical example of this kind of health conditions. Chronic respiratory diseases, cardiovascular diseases, cancer, and diabetes are the most widespread chronic conditions worldwide (World Health Organization 2015). Their burden is a common challenge for developing and developed countries; because of their huge health and economic costs, they constitute one of the main challenges for healthcare systems around the world. Together, they account for more than 30 million of deaths of people between the ages 30 and 70 years (World Health Organization 2017). Hundreds of millions of people suffer from chronic respiratory diseases worldwide (World Health Organization 2008a) and diabetes (International Diabetes Federation 2018), while in middle- and low-income countries, the percentage of deaths ascribed to cardiovascular diseases is nearly $30 \%$ of the all-cause mortality (World Health Organization 2008b). New cases of worldwide cancer are estimated around 14.1 million of people each year (Cancer Research UK 2018). Globally, most deaths for chronic diseases might be avoided or at least delayed by implementing and delivering effective interventions aimed at preventing or controlling these conditions.

\section{Risk Factors for Chronic Diseases}

The first necessary step in the effective prevention of each chronic condition is the identification of substantial risk factors for its onset, development, and progression (World Health Organization 2009). Several risk factors for chronic diseases have been described, and they can be classified as non-modifiable and modifiable risk factors. The first ones refer to causes and conditions out of people's control and that could not be changed or treated. Age, gender, ethnicity, genetic, and family history (cfr. Chap. 4) are among the most important and common non-modifiable risk factors for several chronic diseases, such as cardiovascular diseases (Sharkey and Modarai 2018), cancer (Nindrea et al. 2018; World Health Organization 2015), chronic obtrusive respiratory disease (Singanayagam et al. 2013), and type 2 diabetes (Seuring et al. 2015). On the other hand, modifiable risk factors are aspects that could be treated, controlled, and changed and that are, at least at some degree, under subjects' will. They include overweight or obesity, cigarette smoking, physical inactivity, high-cholesterol or lipid levels, and high blood pressure. These modifiable risk factors can be targeted efficiently by implementing effective interventions to promote health, salutogenic lifestyles, and behavioral change. It is also relevant to stress that a bunch of modifiable risk factors are responsible for the onset and progression of several health chronic conditions. For example, cardiovascular 
diseases, obtrusive respiratory conditions, diabetes, and cancer share the same modifiable risk factors. Specifically, the most deadly modifiable risk factors for these chronic conditions are hypertension (responsible for more than 10\% of global deaths each year), tobacco (9\%), hypercholesterolemia (6\%), sedentariness, and obesity (5\%) (World Health Organization 2009).

\section{Primary, Secondary, and Tertiary eHealth Prevention}

Each eHealth prevention intervention could be adequately described by considering a bunch of conceptual and practical aspects that were commonly used to elucidate differences among traditional preventive efforts. The first distinction refers to primary, secondary, and tertiary prevention (Institute for Work and Health 2018). Specifically, primary prevention is aimed at preventing diseases and medical conditions before they occur. Primary preventive efforts try to avoid the exposures to environmental risk, inform and educate people about unsafe and healthy habits, and target modifiable risk factors, such as unsafe behaviors or unhealthy habits, through lifestyle modification. For example, several mHealth interventions have been implemented to promote healthy sun-related behaviors and attitudes to prevent skin cancer (for a review, see Finch et al. 2016). These interventions were primarily informative and educational about the risk of unprotected exposure to the UV radiation and were delivered through daily text messages, e-mails, and written reminders asking people to apply sunscreen protection. Secondary preventive efforts are aimed at reducing the impact of disease or medical conditions through their early detection and treatment in order to mitigate their impact and slowdown progression. eHealth secondary prevention interventions especially focus on monitoring symptomatology and promoting screening behavior. Prototypical examples of eHealth secondary prevention are mobile applications aimed at facilitating early detection of melanoma in people at high risk for developing melanoma by promoting annual total body skin exams and instructing about the skin self-examination (for a review, see Wu et al. (2016)). Specifically, the SkinVision mHealth, an integrated risk assessment algorithm for melanocytic lesions and melanoma detection, evaluates picture taken with the smartphone camera and then gives user useful information about each lesion and its associated risk for developing skin cancer (Thissen et al. 2017; Udrea and Lupu 2014). From this point of view, this mobile app could be a useful eHealth secondary prevention effort to detect melanoma in early stages, mitigate its possible progression, and then potentially reduce rates of mortality for skin cancer. Finally, tertiary prevention interventions focus especially on patients' selfmanagement abilities, efficient proactive strategies, and lifestyle modification to prevent recurrence, progression, and long-term severe outcomes of the disease. The specific aim of this kind of eHealth intervention is to soften the impact of an ongoing chronic disease or medical conditions. Tertiary prevention intervention through mobile technologies was recently implemented to promote self-management abilities, self-care, and glycemic control in patients with type 2 diabetes (for a review, 
see $\mathrm{Wu}$ et al. (2018)). These mobile apps permit patients to monitor automatically and real-time the glucose level through a wireless glucometer, store this information in the smartphone, and receive personalized information with remainders, motivational message, and indication about lifestyle modifications.

\section{Population-Based vs. Individual-Based eHealth Prevention}

Alongside classification among primary, secondary, and tertiary prevention, eHealth prevention intervention could be categorized by referring to the specific target population of their preventive effort. Specifically, the epidemiologist Geoffrey Rose proposed a relevant distinction among different strategies for the prevention of chronic conditions and health problems. He stated that preventive efforts could be efficiently implemented by adopting one of the two main approaches or strategies to prevention: the population-based and the individual high-risk approaches (Rose 1995). The first one targets the entire population with health promotion actions and activities that prevent disease and negative outcomes through the implementation of policies and interventions aimed at promoting population-based behavioral change and healthy lifestyle and influencing the physical, social, and economic environment. Through the adoption of new technologies, innovative eHealth prevention interventions could be potentiality delivered to a wider audience than the one reached with traditional approaches for the prevention of chronic diseases. One example of a population-based mHealth preventive strategy is the Stroke Riskometer app for the primary prevention (Feigin et al. 2015, 2017; Parmar et al. 2015). This mobile application informs the general population about individual and overall risk for stroke, educates people about warning signs of stroke, and empowers them with effective strategies to reduce their cardiovascular risk by providing evidence-based and internationally recognized guidelines about pharmacological treatment and behavioral change.

Conversely, in accordance with the P5 approach, the individual high-risk approach aimed at firstly identifying individuals with high risk for developing diseases or negative outcomes and then targeting this specific population with ad hoc preventive interventions. This kind of prevention strategies focuses especially on individuals with high level of known risk factor for chronic diseases or people that show premorbid signs prior to the onset of illness. Subsequently, personalized health education, health promotion, and behavioral change interventions are delivered to promote healthy lifestyles and reduce risk factors and premorbidity. The adoption of new technologies has the potentiality of boosting the implementation of personalized interventions in medicine (Cutica et al. 2014; Renzi et al. 2016), because they offer unique opportunities to personalize contents and stimuli (Pizzoli et al. 2019). For example, innovative technologies obtain a clear and real-time picture of each individual by taking into account individual risk factor, behaviors, abilities, and needs and then tailor preventive efforts to this specific individual and disease profile (Vergani et al. 2019). One example of an innovative eHealth preven- 
tion intervention is the Consumer Navigation of Electronic Cardiovascular Tool (CONNECT; Coorey et al. 2017; Redfern et al. 2014). It is a web application, accessible via a mobile device or computer, delivering a multicomponent and personalized eHealth prevention effort to empower people with moderate-to-high cardiovascular risk in opting for or increasing treatment adherence and healthy lifestyle modifications. CONNECT enables the real-time calculation of individual risk score for cardiovascular diseases. Other core features of this eHealth individual high-risk intervention are tracking of actual behaviors, interactive educational resources about risks and benefits of lifestyle, and delivering of tailored healthy habit recommendations and motivational messages for effective behavioral changes.

\section{5 eHealth Behavioral Change Interventions}

Behavioral change techniques and personalized motivational factors for lifestyle modification are among the most common core features of several eHealth interventions to prevent the onset and progression of illnesses. Specifically, the most innovative and promising approaches deliver traditional, theoretical, and evidence-based behavioral change interventions by means of new and digital technologies, such as mobile applications, websites, text messages, and serious games. For what concern behavioral change intervention, starting from the 1950s, several theories and models of behavioral change have been proposed to effectively target healthcompromising habits responsible for the onset and progression of acute and chronic diseases. The Health Belief Model (Rosenstock 1974), the Social Cognitive Theory (Bandura 1977), the Transtheoretical Model (Prochaska and Diclemente 1983; Prochaska and Velicer 1997), and the Health Action Process Approach (Schwarzer 1992, 2008; Schwarzer et al. 2011) are the most known clinically and empirically grounded theories of behavioral change. Meta-analytical results demonstrated the superiority, in comparison with usual primary health care, of theoretically based health behavioral change interventions in promoting healthier lifestyle in terms of reduced intake of calories and saturated fats, improvement in intensity and frequency of physical activity, and smoking cessation (Bully et al. 2015). Each model has its specificity in promoting lifestyle modifications (for a brief overview, see Stroebe (2011)). Even if there are radical theoretical and conceptual differences among these models, all of them stress the role of personal control and self-efficacy belief in promoting lifestyle modifications. Specifically, as the P5 approach highlights, they suggest that individuals are more likely to change unhealthy behaviors and to maintain lifestyle modification over time when they perceive themselves as able to effectively succeed in these tasks (Bandura 1977, 1982). For example, people are more likely to quit smoking when they have strong beliefs about their ability to abstain from smoking and maintain abstinence (Gwaltney et al. 2013). Furthermore, self-efficacy beliefs seem to shape the relationship between perceived health satisfaction and illness severity in cardiovascular diseases (Greco et al. 2015; Steca et al. 2013, 2015). As we will deepen in the next section, eHealth 
interventions have been developed by taking advantage of the technical capabilities of web-based and mobile technologies to track real-time behavioral and health information, involve the healthcare providers, leverage peer and social influence, and increase the accessibility of health information to deliver more effective preventive interventions (Klasnja and Pratt 2012). These technical features are especially useful for the promotion of people's self-efficacy, one of the main core features of both traditional and eHealth preventive interventions, because they permit the realtime monitoring of actual behaviors and then deliver personalized vicarious experience, modeling, and tailored feedbacks. Other determinants of intention to change and actual lifestyle modification have been proposed in the main behavioral change theories. Among these determinants, the most relevant are perceived risk or vulnerability, attitude toward unhealthy and healthy behaviors, and outcome expectancy (Stroebe 2011). Starting from this theoretical knowledge and empirical evidence, several eHealth interventions have approached the prevention of chronic diseases by taking advantage of technical solutions introduced by new media. These eHealth interventions have the qualities of engaging users deeply, permitting an easy integration between usual care and self-management practices, obtaining real-time and online monitoring of clinical outcomes and behaviors, and personalizing feedback and motivational messages to users (Kebede et al. 2017).

Even if some preventive interventions apply theoretical knowledge on behavioral change, two recent meta-analyses on the use of lifestyle modification in web-based and mobile interventions for self-management respectively of asthma (Al-Durra et al. 2015) and type 2 diabetes (Van Vugt et al. 2013) highlighted that a considerable proportion of eHealth preventive efforts does not adopt any documented and empirical-based behavioral change theories. The remaining eHealth interventions adopt the Health Belief Model (Rosenstock 1974), the Transtheoretical Model (Prochaska and Diclemente 1983; Prochaska and Velicer 1997), and the SelfEfficacy and Social-Cognitive Model (Bandura 1977, 1982), alongside with gamification and tailored communication, to promote self-management, self-care, and healthy habits in this kind of patients.

Upon reviewing the literature on mHealth behavioral interventions to counteract physical inactivity and sedentary habits, Direito et al. (2017) highlighted that there is a strong heterogeneity in the terminology used to describe behavioral change interventions. Specifically, in detailing their interventions, developers are more likely to refer to specific core features and strategies rather than reporting actual behavioral change theories and models. Specifically, the vast majority of interventions adopted goal setting, alongside with self-monitoring, social support, feedbacks, and educational components, to foster moderate-to-vigorous physical activity. This kind of techniques implicates the development of a detailed action plan to motivate and orient people toward a meaningful goal (Bryan and Locke 1967; Latham and Locke 2009; Locke and Latham 2006). Goal setting involves the development of an action plan designed to motivate and guide people in goal pursuit. Thus, individuals are educated to establish clear objective about behavioral change, instructed on how to efficiently pursue them, and constantly motivated to 
reach these specific health-related goals. The importance of establishing clear and detailed objectives for effective behavioral change has been acknowledged by a few eHealth preventive programs that have implemented the SMART criteria. Specifically, SMART goals - which stands for "Specific, Measurable, Achievable, Relevant, and Time Bound" - are the best type of goals to be set (Macleod 2013; Moskowitz and Halvorson 2009). This technique has been implemented in the strengthening and stretching (mySARAH; Srikesavan et al. 2018), an online tertiary preventive effort for people suffering from rheumatoid arthritis of the hand. This web-based program includes educational videos about upper limb mobility exercise and strength exercise for hands. Adherence to the exercise plan is fostered with behavioral support strategies of self-monitoring, goal setting, SMART goals, and action planning. Specifically, patients are asked to set SMART goals about exercise, plan their workout schedule, and constantly review their SMART goals on the basis of actual behaviors and performance.

Overall, in most cases, there is still a lack of evidence-based and solid theoretical foundations of eHealth prevention interventions. However, regardless of the specific behavioral change model being adopted, web-based behavioral change interventions have been demonstrated to be more effective than traditional ones in increasing knowledge about nutrition and physical exercise and people's awareness about health risk factors and individual risk and in promoting subsequent lifestyle modification in terms of being more active and having an healthy diet (Wantland et al. 2004). For example, wearable devices, such activity and sleep trackers and blood pressure and heart monitors, bring new possibilities in delivering effective and tailored behavioral change interventions to increase the frequency and intensity of physical exercise. Results of a recent meta-analysis showed that behavioral change interventions comprising both wearable devices and mobile applications are effective in promoting physical activity, measured through objective measure and daily step count, in the general population (Gal et al. 2018).

To sum up, while several eHealth preventive programs have been developed without referring to a specific theory of behavioral change, the adoption of a solid theoretical foundation is a necessary and preliminary step in the development of this kind of interventions. The selection of the specific behavioral change theory or technique to be implemented in eHealth preventive program aimed at promoting lifestyle modification should be facilitated by considering the classification proposed by Michie and colleagues (Michie et al. 2011, 2013). Specifically, upon reviewing the literature on traditional health behavioral change, they developed an extensive and useful taxonomy of 93 hierarchically clustered techniques that could be used to implement lifestyle modification interventions through eHealth modalities. As stated by Van Vugt et al. (2013), the selection of the specific technology of an eHealth intervention is secondary and should follow the decision about the specific behavioral change theory or strategy to be implemented. All these steps must be guided by a critical evaluation of theories, empirical evidence, contextual background, and specific nature of the behavior to be targeted. 


\section{Strategies of eHealth Prevention}

The classification proposed by Michie and colleagues highlighted a huge heterogeneity in strategies being implemented in traditional intervention programs aimed at promoting preventive habits and lifestyle modifications. Specifically, through a consensus exercise involving more than 50 experts in implementing and delivering lifestyle modification interventions, they developed a list of 93 strategies to promote behavioral change. These methods have been subsequently clustered into high-order classes of (1) reinforcement (e.g., punishment, response cost, chaining), (2) reward and threat (e.g., social and self-reward), (3) repetition and substitution (e.g., Behavioral substitution, habit formation, and reversal), (4) antecedents (e.g., restructuring the social and physical environment), (5) associative learning (e.g., exposure, classical conditioning, and prompt cues), (6) covert learning (e.g., vicarious reinforcement and convert conditioning), (7) consequences (e.g., salience of consequences, health and emotional consequences), (8) feedback and monitoring (e.g., feedback on behavior, biofeedback, and self-monitoring of behavior), (9) goals and planning (e.g., action planning including implementation intention and goal setting), (10) social support (e.g., practical and emotional support), (11) comparison of behavior (e.g., modeling of behavior and social comparison, (12) selfbelief (e.g., self-task, focus on past success, and verbal persuasion to boost self-efficacy), (13) comparison of outcomes (e.g., persuasive argument, pros, and cons), (14) identity (e.g., self-affirmation and cognitive dissonance), (15) shaping knowledge (e.g., reattribution and instructions on how to perform a behavior), and (16) regulation (e.g., regulate negative emotions, pharmacological support, and conserving mental resources) (for a review, see Michie et al. (2011, 2013)).

The vast majority of these overarching strategies have been transferred and adapted to deliver eHealth prevention and behavioral change intervention while taking advantage of the technical capabilities of the World Wide Web, personal computers, smartphones and mobile apps, and wearable devices. In 2012, Klasnja and Pratt (2012) developed a concise taxonomy of strategies that have been generally used in mobile-based healthcare interventions. Specifically, four of these core strategies might be used to describe each eHealth prevention effort: (1) promoting health information and awareness, (2) tracking behavioral and health information, (3) leveraging social influence, and (4) utilizing entertainment and gamification. Generally, effective eHealth preventive efforts rely on a peculiar combination of two or more of these strategies.

One of the core components of most eHealth interventions (and also of the P5 approach) is educational and information feature aimed at promoting awareness and knowledge about health and risk factor for the onset and progression of chronic diseases and reminding and motivating users or patients to promote their selfmanagement abilities, treatment adherence, and behavioral change. New media technologies permit to deliver health information to a wider audience than the one possible reached by traditional prevention program. Web-based and interactive 
educational efforts that allow users to navigate through online information on their own are effective in increasing self-management abilities and self-care habits for the secondary and tertiary prevention of illnesses and medical conditions (Fredericks et al. 2015; Webb et al. 2010). This kind of interventions is especially useful for the prevention of chronic diseases because it allows people to access autonomously relevant health information and decide the type and amount of data they are willing to consult. For example, HeartCare is an intervention dealing with the secondary and tertiary prevention of chronic cardiac diseases. It is a web-based tool aimed at improving self-care and adherence to treatment by allowing patients to access useful information on their disease, medication, and behavioral recommendations, in terms of diet and physical activity (Brennan et al. 2001, 2010). This kind of webbased educational intervention is more cost-effective than the traditional ones in delivering evidence-based and specialized health information to acute and chronic patients (Brennan et al. 2010; Côté et al. 2011; Martorella et al. 2012; Runge et al. 2006). Indeed, educational eHealth interventions strongly rely on the involvement and engagement of people that are requested to actively search and autonomously consult information about their health and behaviors.

On the contrary, other technologies, such as text messages and notifications from mobile apps, permit to deliver health information, prompts, and reminders to people that receive them without any active searching or commitment and permit to provide information at the right time (e.g., at dinner time when patients should take medications). Text messages and notifications could be used as (1) educational content, (2) prompts to remind patients to take their medications, and (3) tips to motivate them to behavioral change. For example, daily phone text messages have been used to promote self-care and adherence to treatment in people suffering from chronic respiratory diseases (Strandbygaard et al. 2010). General educational messages are used to inform users or patients about their health condition, symptomatology, possible preventive efforts, and lifestyle modification that could counteract the onset or progression of medical conditions (Beratarrechea et al. 2017; Orr and King 2015). The adoption of eHealth modalities allows the easy implementation of tailored or personalized communication that, compared to generic information, is more effective in promoting lifestyle modification and screening behaviors (Ovbiagele et al. 2015). Moreover, text messages and notifications might be used as prompts to remind users and patients to take medications or to engage in a specific behavior. This is particularly useful in behavioral change interventions to increase users' perseverance and consistency in performing preventive and health-promoting actions that they are very likely to forget to do. Finally, personalized education and informative contents could be also used as tips or advices to motivate users to change their unhealthy behaviors or be adherent to treatment by teaching them effective strategies on how to counteract to obstacles and difficulties interfering with adherence and behavioral change (Gerber et al. 2009).

Nowadays, mobile applications and new wearable devices allow the constant and automated monitoring of users' behaviors and clinical conditions, in accordance 
with the P5 approach. The key core of many eHealth prevention interventions takes advantage from the possibility to easily track physiological parameters, healthrelated behaviors, and psychological states. Patients could track and record all these data by (1) using automated sensors and (2) actively logging behaviors, health information, and medication. Self-monitoring is a viable strategy to prevent illness and foster healthy behavioral change by promoting patients' awareness about their own health and health-related behaviors, motivating users in treatment adherence and behavioral change recommendations, and promoting frequency of healthy habits (Consolvo et al. 2008; Gasser et al. 2006; Nelson 1977; Ness et al. 2007). Furthermore, constant and recorded information on physiological parameters allow and facilitate the participation and inclusion of informal caregivers and healthcare providers in patients' self-management process. This feature is especially relevant for the secondary and tertiary prevention because people suffering from chronic diseases are generally required to monitor their symptomatology, adhere to complex treatment, and maintain healthy habits. A bunch of eHealth intervention monitor patients' conditions and alert healthcare providers or informal caregivers where severe clinical outcome has been detected. For example, a complex system of wearable devices consisting of a high blood pressure bracelet, ECG sensor, and accelerometers permits patients with chronic heart failure or heart diseases to automatically record their health status (Rubel et al. 2004, 2005; Villalba Mora et al. 2006, 2009). Informal caregivers and the healthcare team are automatically contacted if necessary. As mentioned above, accelerometer, activity and sleep trackers, blood and heart rate sensors, and step counter integrated in many smartphones are useful wearable devices that foster the possibilities of new eHealth preventive efforts to increase behavioral change, especially in terms of increasing physical exercise (Gal et al. 2018). Self-monitoring is also an effective way to promote weight management for the prevention of obesity and overweight problems in adult populations (Burke et al. 2011; Madigan et al. 2015; Zheng et al. 2015). As highlighted by a recent meta-analysis by Ho et al. (2018), many eHealth programs delivered web-based self-monitoring to prevent obesity during adolescence as well. All these assessed studies employed logging of behaviors and health information that, differently from automated tracking of personal information through wearable devices, requires users to provide and record all the relevant health-related data. Specifically, adolescents are asked to daily log information about their diet, physical activity, and weight. Results suggested that daily self-monitoring, supported by goal setting and face-to-face counseling, is effective in reducing adolescents' body mass index.

Besides being positive influenced by individual engagement and active effort, the effective health promotion, lifestyle modifications, and preventive interventions are leveraged by a supportive social environment for patients and users. Specifically, emotional and instrumental social support from partners, relatives, and friends may facilitate self-care, behavioral change, and adherence to treatment in healthy people and patients with chronic diseases (Finlay et al. 2018; Holt-Lunstad 2018; Lange et al. 2018; Tregarthen et al. 2015; Uchino et al. 2018). By recognizing the pivotal role of social influence and support for the effectiveness of each preventive effort, 
several traditional and eHealth interventions have included specific features aimed at leveraging social influence to promote self-management skills, screening behaviors, lifestyle modifications, and treatment adherence. There are three main strategies that have been implemented within eHealth preventive programs to take advantage of social influence for health promotion by leveraging (1) social support from family and friends (cfr. Chap. 4), (2) peer-to-peer influence, and (3) vicarious experience and peer modeling.

The first strategy might be especially useful for people facing strong difficulties in changing their unhealthy habits or maintaining an adequate self-care. In this case, close relatives and friends may support and motivate those people in accomplishing their health-related goals and improving their self-management skills. An eHealth preventive program aimed at helping people quit smoking by leveraging social support from a support person nominated by the quitter is an example of this category (Obermayer et al. 2004). Specifically, this web-based intervention allows the support person to constantly monitor the progress of the quitter and then send the abstinence smoker motivational and supporting text messages. The second strategy aims at leveraging social influence by allowing interaction among people working on the same health-related task. This might be especially useful either for sharing how-to practices, reassurance, encouragement, and information or motivating people through competition. Peer-to-peer social support allows sharing instrumental information on strategies and practical instructions on how to effectively deal with selfcare practices, behavioral change, and adherence to treatment and also foster discussions about feelings and emotions or share encouragement, reflection, and reassurance among users. For example, a bunch of eHealth intervention for the promotion of physical activity have implemented peer-to-peer discussion boards, buddy systems (i.e., two or more people are able to monitor and help each other), live chats, and forums to allow people to motivate each other and share their feelings and thoughts about physical exercise (Webb et al. 2010). On the contrary, other eHealth interventions have adopted peer-to-peer competition to foster motivation in changing unhealthy lifestyles. For example, Mobile Lifestyle Coach app used competition among users to boost their levels of physical activity and their healthy nutritional habits (Gasser et al. 2006). As this mobile app employed also gamification, users were assigned into teams that compete one against the other. The winning team is the one that obtains the higher individual and cumulative scores of healthy habits measured as progress toward daily goals of balanced diet and physical activity. Peer-to-peer influence and social support from family might be powerful strategies to enhance people's self-efficacy in following preventive programs and recommendations for behavioral change. In fact, as clearly stated by Bandura (1977, 1982), people's belief about their ability to succeed in a specific task can be developed by four main sources of influence: (1) mastery or enactive experience (success increases perceived self-efficacy and failure reduces it); (2) vicarious experience or modeling (when people observe someone succeeding in a task, their self-efficacy generally increases); (3) verbal and social persuasion (motivational feedback and direct encouragement from other people might foster individual self-efficacy); and 
(4) physiological factors (perception and belief about sign of distress, such as negative emotion, fatigue, and pain, may alter self-efficacy). eHealth providing peer-topeer influence and social support from family and friends might be especially helpful for people dealing with complex health-related task such as lifestyle modification because these strategies allow people to receive verbal persuasion about their ability to alter given tasks and thus catalyze greater effort. Also the third and last strategy of leveraging social influence through vicarious experience and modeling may be relevant to foster people self-efficacy. Specifically, this approach relies on the power of peer-to-peer exchange of useful information about tips and effective strategies to effectively deal with behavioral change and overcome health-related difficulties. Successful peers are thus competent and proficient models that disseminate effective skills and schemes for managing task demands that consequently raise perceived efficacy. For example, Schweier et al. (2014) have developed a webbased peer-modeling intervention to promote healthy lifestyle changes and selfmanagement ability in German patients with cardiovascular diseases and chronic back pain. Their open access and no-cost website provides more than 1000 texts, audios, and videos of people with coronary heart disease and chronic back pain reporting how they had efficiently modified their unhealthy behaviors focusing on obstacles and their successful strategies in maintaining healthy habits.

Overall, eHealth behavioral change and preventive interventions must face the main challenge of motivating people to act appropriately and to maintain lifestyle modifications over time. It is often hard to motivate healthy but physical inactive people in changing their unhealthy habits. Furthermore, most people are very likely to adhere to an eHealth preventive program only for a short time. However, it is possible to take advantage of the motivational capacity of entertainment content, gamification, and games to keep users engaged (Craig Lefebvre et al. 2010; Gal et al. 2018; Graffigna et al. 2014; McCallum 2012; Sardi et al. 2017). As the P5 approach suggests, the use of entertainment content and gamification has been adopted as one of the four core strategies of many eHealth prevention interventions.

One prototypical example of the power of gamification to motivate people to be more physically active is Pokémon GO, a commercial mobile-augmented reality game that has been proved effective in fostering physical activity in young and inactive people (Althoff et al. 2016; Gabbiadini et al. 2018; Howe et al. 2016). Similarly, gamification has been implemented in REACH for Success, an innovative mHealth prevention and early intervention program targeting anxious symptomatology in youth (Stoll et al. 2017). Specifically, this mobile app relies on gamification to increase people's engagement and adoption of effective self-management strategies for managing stress and anxiety-provoking situations. An animated avatar, shaped like a blob, delivers personalized motivational messages and interacts with the user. This avatar is designed following the Proteus effect positing that animated representation that rewards people for being successful in a task increased motivation to perform such activity (Yee and Bailenson 2007). When users complete daily homework delivered by REACH, they can tap on the blob and see it performing some leveled tricks. 


\section{Conclusion}

This chapter briefly introduced the eHealth approach to the primary, secondary, and tertiary prevention of chronic diseases. Compared to traditional interventions, eHealth prevention programs can offer several additional benefits. Specifically, this kind of interventions takes advantage from the huge functionalities of new technologies that allow people to access easily and briefly health information and educational content, to constantly monitor their health status and behavior, and also to receive real-time and personalized feedbacks about the appropriateness of their actions and about their physiological parameters. Moreover, new media allow an easy and online communication of patients with their caregivers and their peers as well. All these features might be especially relevant in facilitating and motivating people to adopt and maintain healthy lifestyles and subsequently prevent the onset or progression of several chronic conditions. Finally, thanks to the possibility of employing gamification, eHealth interventions might better motivate people to follow preventive and lifestyle modification programs over a long time. For all these reasons, eHealth preventive interventions are promising ways to approach efficiently the primary, secondary, and tertiary prevention of chronic diseases.

Acknowledgment Silvia Francesca Maria Pizzoli is a PhD student within the European School of Molecular Medicine (SEMM).

\section{References}

Al-Durra, M., Torio, M. B., \& Cafazzo, J. A. (2015). The use of behavior change theory in internetbased asthma self-management interventions: A systematic review. Journal of Medical Internet Research, 17(4), e89. https://doi.org/10.2196/jmir.4110.

Althoff, T., White, R. W., \& Horvitz, E. (2016). Influence of pokémon go on physical activity: Study and implications. Journal of Medical Internet Research, 18(12), 1-14. https://doi. org/10.2196/jmir.6759.

Australian Institute of Health and Welfare. (2016). Chronic diseases. Australian Institute of Health and Welfare. Retrieved October 16, 2018, from https://www.aihw.gov.au/reports-data/ health-conditions-disability-deaths/chronic-disease/about.

Baker, D. (2001). Patient-centered healthcare: The role of the internet. Disease Management and Health Outcomes, 9, 411. https://doi.org/10.2165/00115677-200109080-00001.

Bandura, A. (1977). Self-efficacy: Toward a unifying theory of behavioral change. Psychological Review, 84(2), 191-215. https://doi.org/10.1037/0033-295X.84.2.191.

Bandura, A. (1982). Self-efficacy mechanism in human agency. American Psychologist, 37, 122. https://doi.org/10.1037/0003-066X.37.2.122.

Beratarrechea, A., Moyano, D., Irazola, V., \& Rubinstein, A. (2017). mHealth interventions to counter noncommunicable diseases in developing countries. Cardiology Clinics, 35(1), 13-30. https://doi.org/10.1016/j.ccl.2016.08.009.

Brennan, P. F., Casper, G. R., Burke, L. J., Johnson, K. A., Brown, R., Valdez, R. S., ... Sturgeon, B. (2010). Technology-enhanced practice for patients with chronic cardiac disease: Home implementation and evaluation. Heart and Lung: Journal of Acute and Critical Care, 39(6), S34-S46. https://doi.org/10.1016/j.hrtlng.2010.09.003. 
Brennan, P. F., Moore, S. M., Bjornsdottir, G., Jones, J., Visovsky, C., \& Rogers, M. (2001). HeartCare: An internet-based information and support system for patient home recovery after coronary artery bypass graft (CABG) surgery. Journal of Advanced Nursing, 35(5), 699-708. https://doi.org/10.1046/j.1365-2648.2001.01902.x.

Bryan, J. F., \& Locke, E. a. (1967). Goal setting as a means of increasing motivation. The Journal of Applied Psychology, 51(3), 274-277. https://doi.org/10.1037/h0024566.

Bully, P., Sánchez, Á., Zabaleta-del-Olmo, E., Pombo, H., \& Grandes, G. (2015). Evidence from interventions based on theoretical models for lifestyle modification (physical activity, diet, alcohol and tobacco use) in primary care settings: A systematic review. Preventive Medicine, 76(S), S76-S93. https://doi.org/10.1016/j.ypmed.2014.12.020.

Burke, L. E., Wang, J., \& Sevick, M. A. (2011). Self-monitoring in weight loss: A systematic review of the literature. Journal of the American Dietetic Association, 111(1), 92-102. https:// doi.org/10.1016/J.JADA.2010.10.008.

Cancer Research UK. (2018). Worldwide cancer statistics. Cancer Research UK. Retrieved October 16, 2018, from https://www.cancerresearchuk.org/health-professional/cancer-statistics/ worldwide-cancer

Consolvo, S., Klasnja, P., McDonald, D. W., Avrahami, D., Froehlich, J., LeGrand, L., ... Landay, J. A. (2008). Flowers or a robot army?: Encouraging awareness \& activity with personal, mobile displays. In: Proceedings of the 10th international conference on ubiquitous computing (UbiComp '08), (pp. 54-63). https://doi.org/10.1145/1409635.1409644.

Coorey, G. M., Neubeck, L., Usherwood, T., Peiris, D., Parker, S., Lau, A. Y. S., ... Redfern, J. (2017). Implementation of a consumer-focused eHealth intervention for people with moderate-to-high cardiovascular disease risk: Protocol for a mixed-methods process evaluation. BMJ Open, 7(1), e014353. https://doi.org/10.1136/bmjopen-2016-014353.

Côté, J., Ramirez-Garcia, P., Rouleau, G., Saulnier, D., Guéhéneuc, Y. G., Hernandez, A., \& Godin, G. (2011). A nursing virtual intervention: Real-time support for managing antiretroviral therapy. CIN - Computers Informatics Nursing, 29(1), 43-51. https://doi.org/10.1097/ NCN.0b013e3181f9dc02.

Craig Lefebvre, R., Tada, Y., Hilfiker, S. W., \& Baur, C. (2010). The assessment of user engagement with eHealth content: The eHealth engagement scale. Journal of Computer-Mediated Communication, 15(4), 666-681. https://doi.org/10.1111/j.1083-6101.2009.01514.x.

Cutica, I., Vie, G. M., \& Pravettoni, G. (2014). Personalised medicine: The cognitive side of patients. European Journal of Internal Medicine, 25(8), 685-688. https://doi.org/10.1016/j. ejim.2014.07.002.

Direito, A., Carraça, E., Rawstorn, J., Whittaker, R., \& Maddison, R. (2017). mHealth technologies to influence physical activity and sedentary behaviors: Behavior change techniques, systematic review and meta-analysis of randomized controlled trials. Annals of Behavioral Medicine, 51, 226. https://doi.org/10.1007/s12160-016-9846-0.

Evers, K. (2005). eHealth promotion: The use of the internet for health promotion. American Journal of Health Promotion, 20, iii.

Feigin, V. L., Krishnamurthi, R., Bhattacharjee, R., Parmar, P., Theadom, A., Hussein, T., ... Moran, A. E. (2015). New strategy to reduce the global burden of stroke. Stroke, 46(6), 17401747. https://doi.org/10.1161/STROKEAHA.115.008222.

Feigin, V. L., Norrving, B., \& Mensah, G. A. (2017). Primary prevention of cardiovascular disease through population-wide motivational strategies: Insights from using smartphones in stroke prevention. BMJ Global Health, 2(2), e000306. https://doi.org/10.1136/bmjgh-2017-000306.

Finch, L., Janda, M., Loescher, L. J., \& Hacker, E. (2016). Can skin cancer prevention be improved through mobile technology interventions? A systematic review. Preventive Medicine, 90, 121. https://doi.org/10.1016/j.ypmed.2016.06.037.

Finlay, K. A., Peacock, S., \& Elander, J. (2018). Developing successful social support: An interpretative phenomenological analysis of mechanisms and processes in a chronic pain support group. Psychology \& Health, 33(7), 846-871. https://doi.org/10.1080/08870446.2017.14211 88. 
Fotheringham, M. J., Owies, D., Leslie, E., \& Owen, N. (2000). Interactive health communication in preventive medicine: Internet-based strategies in teaching and research. American Journal of Preventive Medicine, 19(2), 113-120. https://doi.org/10.1016/S0749-3797(00)00188-4.

Fredericks, S., Martorella, G., \& Catallo, C. (2015). A systematic review of web-based educational interventions. Clinical Nursing Research, 24(1), 91-113. https://doi. org/10.1177/1054773814522829.

Gabbiadini, A., Sagioglou, C., \& Greitemeyer, T. (2018). Does Pokémon go lead to a more physically active life style? Computers in Human Behavior, 84, 258. https://doi.org/10.1016/j. chb.2018.03.005.

Gal, R., May, A. M., van Overmeeren, E. J., Simons, M., \& Monninkhof, E. M. (2018). The effect of physical activity interventions comprising wearables and smartphone applications on physical activity: a systematic review and meta-analysis. Sports Medicine - Open, 4(1), 42. https:// doi.org/10.1186/s40798-018-0157-9.

Gasser, R., Brodbeck, D., Degen, M., Luthiger, J., Wyss, R., \& Reichlin, S. (2006). Persuasiveness of a Mobile lifestyle coaching application using social facilitation (pp. 27-38). Berlin/ Heidelberg: Springer. https://doi.org/10.1007/11755494_5.

Gerber, B. S., Stolley, M. R., Thompson, A. L., Sharp, L. K., \& Fitzgibbon, M. L. (2009). Mobile phone text messaging to promote healthy behaviors and weight loss maintenance: A feasibility study. Health Informatics Journal, 15(1), 17-25. https://doi.org/10.1177/1460458208099865.

Graffigna, G., Barello, S., Triberti, S., Wiederhold, B. K., Bosio, A. C., \& Riva, G. (2014). Enabling eHealth as a pathway for patient engagement: a toolkit for medical practice. Studies in Health Technology and Informatics, 199, 13-21.

Greco, A., Steca, P., Pozzi, R., Monzani, D., Malfatto, G., \& Parati, G. (2015). The influence of illness severity on health satisfaction in patients with cardiovascular disease: The mediating role of illness perception and self-efficacy beliefs. Behavioral Medicine, 41(1), 9-17.

Gwaltney, C. J., Metrik, J., Shiffman, S., \& Manuscript, A. (2013). Self-efficacy and smoking cessation: A meta-analysis. Psychology of Addictive Behaviors, 23(1), 1729-1737. https://doi. org/10.1037/a0013529.Self-Efficacy.

Ho, T. J. H., Lee, C. C. S., Wong, S. N., \& Lau, Y. (2018). Internet-based self-monitoring interventions for overweight and obese adolescents: A systematic review and metaanalysis. International Journal of Medical Informatics, 120(September), 20-30. https://doi. org/10.1016/j.ijmedinf.2018.09.019.

Holt-Lunstad, J. (2018). Why social relationships are important for physical health: A systems approach to understanding and modifying risk and protection. Annual Review of Psychology, 69, 437. https://doi.org/10.1146/annurev-psych-122216-011902.

Howe, K. B., Suharlim, C., Ueda, P., Howe, D., Kawachi, I., \& Rimm, E. B. (2016). Gotta catch'em all! Pokémon GO and physical activity among young adults: Difference in differences study. BMJ (Online), 355, 1-4. https://doi.org/10.1136/bmj.i6270.

Institute for Work \& Health. (2018). Primary, secondary and tertiary prevention. Institute for Work and Health. Retrieved October 16, 2018, from https://www.iwh.on.ca/ what-researchers-mean-by/primary-secondary-and-tertiary-prevention

International Diabetes Federation. (2018). IDF diabetes atlas - 2017 Atlas. Retrieved October 16, 2018, from http://diabetesatlas.org/resources/2017-atlas.html

Kebede, M., Christianson, L., Khan, Z., Heise, T. L., \& Pischke, C. R. (2017). Effectiveness of behavioral change techniques employed in eHealth interventions designed to improve glycemic control in persons with poorly controlled type 2 diabetes: a systematic review and metaanalysis protocol. Systematic Reviews, 6(1), 211. https://doi.org/10.1186/s13643-017-0609-1.

Klasnja, P., \& Pratt, W. (2012). Healthcare in the pocket: Mapping the space of mobile-phone health interventions. Journal of Biomedical Informatics, 45, 184. https://doi.org/10.1016/j. jbi.2011.08.017.

Lange, D., Corbett, J., Knoll, N., Schwarzer, R., \& Lippke, S. (2018). Fruit and vegetable intake: The interplay of planning, social support, and sex. International Journal of Behavioral Medicine, 25(4), 421-430. https://doi.org/10.1007/s12529-018-9718-z. 
Latham, G. P., \& Locke, E. a. (2009). Science and ethics: What should count as evidence against the use of goal setting? Academy of Management Perspectives, 23(3), 88-91. https://doi. org/10.5465/AMP.2009.43479266.

Locke, E. A., \& Latham, G. P. (2006). New directions in goal-setting theory. Current Directions in Psychological Science, 15(5), 265-268. https://doi.org/10.1111/j.1467-8721.2006.00449.x.

Macleod, L. (2013). Making SMART goals smarter. Physician Executive, 38, 68-70.

Madigan, C. D., Daley, A. J., Lewis, A. L., Aveyard, P., \& Jolly, K. (2015). Is self-weighing an effective tool for weight loss: a systematic literature review and meta-analysis. International Journal of Behavioral Nutrition and Physical Activity, 12(1), 104. https://doi.org/10.1186/ s12966-015-0267-4.

Martorella, G., Côté, J., Racine, M., \& Choinière, M. (2012). Web-based nursing intervention for self-management of pain after cardiac surgery: Pilot randomized controlled trial. Journal of Medical Internet Research, 14(6), e177. https://doi.org/10.2196/jmir.2070.

McCallum, S. (2012). Gamification and serious games for personalized health. Studies in Health Technology and Informatics, 177, 85-96. Retrieved from http://www.ncbi.nlm.nih.gov/ pubmed/22942036.

MedicineNet. (2016). Definition of chronic disease. Retrieved from http://www.medicinenet.com/ script/main/art.asp?articlekey $=33490$

Michie, S., Ashford, S., Sniehotta, F. F., Dombrowski, S. U., Bishop, A., \& French, D. P. (2011). A refined taxonomy of behaviour change techniques to help people change their physical activity and healthy eating behaviours: The CALO-RE taxonomy. Psychology and Health, 26(11), 1479-1498. https://doi.org/10.1080/08870446.2010.540664.

Michie, S., Richardson, M., Johnston, M., Abraham, C., Francis, J., Hardeman, W., ... Wood, C. E. (2013). The behavior change technique taxonomy (v1) of 93 hierarchically clustered techniques: Building an international consensus for the reporting of behavior change interventions. Annals of Behavioral Medicine, 46(1), 81-95. https://doi.org/10.1007/s12160-013-9486-6.

Moskowitz, G. B., \& Halvorson, H. G. (2009). The psychology of goals. Guilford Press. Retrieved from https://www.guilford.com/books/The-Psychology-of-Goals/ Moskowitz-Grant/9781606230299/reviews

Nelson, R. O. (1977). Assessment and therapeutic functions of self-monitoring. In Progress in behaviour modification (Vol. 5, pp. 3-41). Elsevier. https://doi.org/10.1016/ B978-0-12-535605-3.50012-1.

Ness, R. B., Koopman, J. S., \& Roberts, M. S. (2007). Causal system modeling in chronic disease epidemiology: A proposal. Annals of Epidemiology, 17(7), 564-568. https://doi.org/10.1016/j. annepidem.2006.10.014.

Nindrea, R. D., Aryandono, T., Lazuardi, L., \& Dwiprahasto, I. (2018). Diagnostic accuracy of different machine learning algorithms for breast Cancer risk calculation: a meta-analysis. Asian Pacific Journal of Cancer Prevention, 19(7), 1747-1752. https://doi.org/10.22034/ APJCP.2018.19.7.1747.

Obermayer, J. L., Riley, W. T., Asif, O., \& Jean-Mary, J. (2004). College smoking-cessation using cell phone text messaging. Journal of American College Health, 53(2), 71-78. https://doi. org/10.3200/JACH.53.2.71-78.

Orr, J. A., \& King, R. J. (2015). Mobile phone SMS messages can enhance healthy behaviour: a meta-analysis of randomised controlled trials. Health Psychology Review, 9, 397-416. https:// doi.org/10.1080/17437199.2015.1022847.

Ovbiagele, B., Jenkins, C., Patel, S., Brunner-Jackson, B., Anderson, A., Saulson, R., \& Treiber, F. (2015). Mobile health medication adherence and blood pressure control in recent stroke patients. Journal of the Neurological Sciences, 358, 535. https://doi.org/10.1016/j.jns.2015.10.008.

Parmar, P., Krishnamurthi, R., Ikram, M. A., Hofman, A., Mirza, S. S., Varakin, Y., ... Feigin, V. L. (2015). The stroke Riskometer ${ }^{\mathrm{TM}}$ App: Validation of a data collection tool and stroke risk predictor. International Journal of Stroke, 10(2), 231-244. https://doi.org/10.1111/ijs.12411. 
Pizzoli, S., Mazzocco, K., Triberti, S., Monzani, D., Alcañiz Raya, M. L., \& Pravettoni, G. (2019). User-centered virtual reality for promoting relaxation: An innovative approach. Frontiers in Psychology, 10, 479. https://doi.org/10.3389/fpsyg.2019.00479.

Prochaska, J., \& Diclemente, C. (1983). Stages and processes of self-change of smoking - toward an integrative model of change. Journal of Consulting and Clinical Psychology, 51, 390. https://doi.org/10.1037//0022-006X.51.3.390.

Prochaska, J., \& Velicer, W. F. (1997). The transtheoretical model of health behavior change. American Journal of Health Promotion, 12(1), 38-48. https://doi. org/10.4278/0890-1171-12.1.38.

Redfern, J., Usherwood, T., Harris, M. F., Rodgers, A., Hayman, N., Panaretto, K., ... Peiris, D. (2014). A randomised controlled trial of a consumer-focused e-health strategy for cardiovascular risk management in primary care: The consumer navigation of electronic cardiovascular tools (CONNECT) study protocol. BMJ Open, 4(2), 1-9. https://doi.org/10.1136/ bmjopen-2013-004523.

Renzi, C., Riva, S., Masiero, M., \& Pravettoni, G. (2016). The choice dilemma in chronic hematological conditions: Why choosing is not only a medical issue? A psycho-cognitive perspective. Critical Reviews in Oncology/Hematology, 99, 134. https://doi.org/10.1016/j. critrevonc.2015.12.010.

Rose, G. (1995). The strategy of preventive medicine. New York: Oxford University Press.

Rosenstock, I. M. (1974). Historical origins of the health belief model. Health Education Monographs, 2(4), 328-335.

Rubel, P., Fayn, J., Nollo, G., Assanelli, D., Li, B., Restier, L., ... Chevalier, P. (2005). Toward personal eHealth in cardiology. Results from the EPI-MEDICS telemedicine project. Journal of Electrocardiology, 38(4), 100-106. https://doi.org/10.1016/j.jelectrocard.2005.06.011.

Rubel, P., Fayn, J., Simon-Chautemps, L., Atoui, H., Ohlsson, M., Telisson, D., ... Chevalier, P. (2004). New paradigms in telemedicine: Ambient intelligence, wearable, pervasive and personalized. In Wearable eHealth systems for personalised health management: State of the art and future challenges (Vol. 108). Fairfax: IOS Press.

Runge, C., Lecheler, J., Horn, M., Tews, J.-T., \& Schaefer, M. (2006). Outcomes of a web-based patient education program for asthmatic children and adolescents. Chest, 129(3), 581-593. https://doi.org/10.1378/chest.129.3.581.

Sardi, L., Idri, A., \& Fernández-Alemán, J. L. (2017). A systematic review of gamification in e-health. Journal of Biomedical Informatics, 71, 31. https://doi.org/10.1016/j.jbi.2017.05.011.

Schwarzer, R. (1992). Self-efficacy in the adoption and maintenance of health behaviors: Theoretical approaches and a new model. In Self-efficacy: Thought control of action. Washington: Hemisphere.

Schwarzer, R. (2008). Modeling health behavior change: How to predict and modify the adoption and maintenance of health behaviors. Applied Psychology, 57(1), 1-29. https://doi. org/10.1111/j.1464-0597.2007.00325.x.

Schwarzer, R., Lippke, S., \& Luszczynska, A. (2011). Mechanisms of health behavior change in persons with chronic illness or disability: The health action process approach (HAPA). Rehabilitation Psychology, 56(3), 161-170. https://doi.org/10.1037/a0024509.

Schweier, R., Romppel, M., Richter, C., Hoberg, E., Hahmann, H., Scherwinski, I., ... Grande, G. (2014). A web-based peer-modeling intervention aimed at lifestyle changes in patients with coronary heart disease and chronic back pain: Sequential controlled trial. Journal of Medical Internet Research, 16(7), 1-14. https://doi.org/10.2196/jmir.3434.

Seuring, T., Archangelidi, O., \& Suhrcke, M. (2015). The economic costs of type 2 diabetes: A global systematic review. Pharmaco Economics, 33(8), 811-831. https://doi.org/10.1007/ s40273-015-0268-9.

Sharkey, A. R., \& Modarai, B. (2018). Medical management of risk factors for vascular disease. Surgery (United Kingdom), 36(6), 265-271. https://doi.org/10.1016/j.mpsur.2018.03.007.

Singanayagam, A., Schembri, S., \& Chalmers, J. D. (2013). Predictors of mortality in hospitalized adults with acute exacerbation of chronic obstructive pulmonary disease: A systematic 
review and meta-analysis. Annals of the American Thoracic Society, 10(2), 81-89. https://doi. org/10.1513/AnnalsATS.201208-043OC.

Srikesavan, C., Williamson, E., Cranston, T., Hunter, J., Adams, J., Lamb, E., \& S. (2018). An online hand exercise intervention for adults with rheumatoid arthritis (mySARAH): Design, development, and usability testing. JMIR Rehabilitation and Assistive Technologies, 20, e10457. https://doi.org/10.2196/10457.

Steca, P., Greco, A., D’Addario, M., Monzani, D., Pozzi, R., Villani, A., ... \& Parati, G. (2013). Relationship of illness severity with health and life satisfaction in patients with cardiovascular disease: The mediating role of self-efficacy beliefs and illness perceptions. Journal of Happiness Studies, 14(5), 1585-1599.

Steca, P., Greco, A., Cappelletti, E., D’addario, M., Monzani, D., Pancani, L., .. \& Parati, G. (2015). Cardiovascular management self-efficacy: Psy-chometric properties of a new scale and its usefulness in a rehabilitation context. Annals of Behavioral Medicine, 49(5), 660-674.

Stoll, R. D., Pina, A. A., Gary, K., \& Amresh, A. (2017). Usability of a smartphone application to support the prevention and early intervention of anxiety in youth. Cognitive and Behavioral Practice, 24, 393. https://doi.org/10.1016/j.cbpra.2016.11.002.

Strandbygaard, U., Thomsen, S. F., \& Backer, V. (2010). A daily SMS reminder increases adherence to asthma treatment: A three-month follow-up study. Respiratory Medicine, 104(2), 166171. https://doi.org/10.1016/j.rmed.2009.10.003.

Stroebe, W. (2011). Social psychology and health. McGraw-Hill Education. Retrieved from https:// xpv.uab.cat/pub/quapsi/DanaInfo=.adefCyfhGkj3+02113481v12n1p7.pdf

Thissen, M., Udrea, A., Hacking, M., von Braunmuehl, T., \& Ruzicka, T. (2017). mHealth app for risk assessment of pigmented and nonpigmented skin lesions-A study on sensitivity and specificity in detecting malignancy. Telemedicine and E-Health. https://doi.org/10.1089/ tmj.2016.0259.

Tregarthen, J. P., Lock, J., \& Darcy, A. M. (2015). Development of a smartphone application for eating disorder self-monitoring. International Journal of Eating Disorders, 48(7), 972-982. https://doi.org/10.1002/eat.22386.

Uchino, B. N., Bowen, K., Kent de Grey, R., Mikel, J., \& Fisher, E. B. (2018). Social support and physical health: Models, mechanisms, and opportunities. In Principles and concepts of behavioral medicine (pp. 341-372). New York: Springer New York. https://doi. org/10.1007/978-0-387-93826-4_12.

Udrea, A., \& Lupu, C. (2014). Real-time acquisition of quality verified nonstandardized color images for skin lesions risk assessment - A preliminary study. 2014 18th international conference on system theory, control and computing, ICSTCC 2014, (February 2016), (pp. 199-204). https://doi.org/10.1109/ICSTCC.2014.6982415.

Van Vugt, M., De Wit, M., Cleijne, W. H. J. J., \& Snoek, F. J. (2013). Use of behavioral change techniques in web-based self-management programs for type 2 diabetes patients: Systematic review. Journal of Medical Internet Research, 15(12), e279. https://doi.org/10.2196/jmir.2800.

Vergani, L., Marton, G., Pizzoli, S., Monzani, D., Mazzocco, K., \& Pravettoni, G. (2019). Training cognitive functions using mobile apps in breast Cancer patients: Systematic review. JMIR mHealth and uHealth, 7(3), e10855. https://doi.org/10.2196/10855.

Villalba Mora, E., Ottaviano, M., Arredondo, M., Martinez, A., \& Guillen, S. (2006). Wearable monitoring system for heart failure assessment in a mobile environment. Computers in Cardiology, 33, 237-240.

Villalba Mora, E., Salvi, D., Ottaviano, M., Peinado, I., Arredondo, M., \& Akay, A. (2009). Wearable and mobile system to manage remotely heart failure. In Information technology in biomedicine, IEEE transactions on (Vol. 13). New York: Institute of Electrical and Electronics Engineers. https://doi.org/10.1109/TITB.2009.2026572.

Wantland, D. J., Portillo, C. J., Holzemer, W. L., Slaughter, R., \& McGhee, E. M. (2004). The effectiveness of web-based vs. non-web-based interventions: A meta-analysis of behavioral change outcomes. Journal of Medical Internet Research, 6(4), e40. https://doi.org/10.2196/ jmir.6.4.e40. 
Webb, T. L., Joseph, J., Yardley, L., \& Michie, S. (2010). Using the internet to promote health behavior change: A systematic review and meta-analysis of the impact of theoretical basis, use of behavior change techniques, and mode of delivery on efficacy. Journal of Medical Internet Research, 12(1), 1-18. https://doi.org/10.2196/jmir.1376.

World Health Organization. (2008a). Chronic respiratory diseases. Aids Research Programme, 1, 001-156. https://doi.org/10.1136/jech.47.1.4.

World Health Organization. (2008b). The global burden of disease: Update. Geneva: World Health Organization.

World Health Organization. (2009). Mortality and burden of disease attributable to selected major risks. doi:https://doi.org/10.2471/BLT.09.070565.

World Health Organization. (2015). Integrated chronic disease prevention and control. Retrieved October 16, 2018, from http://www.who.int/chp/about/integrated_cd/en/

World Health Organization. (2017). Progress monitor 2017. World Health Organization. Retrieved October 16, 2018, from https://apps.who.int/iris/bitstream/han dle/10665/258940/9789241513029-eng.pdf;jsessionid=68B0EAA3447DE6AE4E2C2026981 5D6BB? sequence $=1$

Wu, I. X. Y., Kee, J. C. Y., Threapleton, D. E., Ma, R. C. W., Lam, V. C. K., Lee, E. K. P., ... Chung, V. C. H. (2018). Effectiveness of smartphone technologies on glycaemic control in patients with type 2 diabetes: Systematic review with meta-analysis of 17 trials. Obesity Reviews : An Official Journal of the International Association for the Study of Obesity, 19(6), 825-838. https://doi.org/10.1111/obr.12669.

Wu, Y. P., Aspinwall, L. G., Conn, B. M., Stump, T., Grahmann, B., \& Leachman, S. A. (2016). A systematic review of interventions to improve adherence to melanoma preventive behaviors for individuals at elevated risk. Preventive Medicine, 88, 153. https://doi.org/10.1016/j. ypmed.2016.04.010.

Yee, N., \& Bailenson, J. (2007). The Proteus effect: The effect of transformed selfrepresentation on behavior. Human Communication Research, 33(3), 271-290. https://doi. org/10.1111/j.1468-2958.2007.00299.x.

Zheng, Y., Klem, M. L., Sereika, S. M., Danford, C. A., Ewing, L. J., \& Burke, L. E. (2015). Self-weighing in weight management: A systematic literature review. Obesity, 23(2), 256-265. https://doi.org/10.1002/oby.20946.

Open Access This chapter is licensed under the terms of the Creative Commons Attribution 4.0 International License (http://creativecommons.org/licenses/by/4.0/), which permits use, sharing, adaptation, distribution and reproduction in any medium or format, as long as you give appropriate credit to the original author(s) and the source, provide a link to the Creative Commons license and indicate if changes were made.

The images or other third party material in this chapter are included in the chapter's Creative Commons license, unless indicated otherwise in a credit line to the material. If material is not included in the chapter's Creative Commons license and your intended use is not permitted by statutory regulation or exceeds the permitted use, you will need to obtain permission directly from the copyright holder.

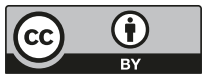

